\title{
Realisasi LNA Dua Tingkat dengan Teknik Penyesuai Impedansi Trafo $\lambda / 4$ dan Lumped Element untuk DVB-T2
}

\author{
ASEP KARYANA ${ }^{1}$, YUYUN SITI ROHMAH ${ }^{1}$, BUDI PRASETYA ${ }^{2}$ \\ 1Program Studi D3 Teknologi Telekomunikasi, Universitas Telkom, Indonesia \\ 2Program Studi S1 Teknik Telekomunikasi, Universitas Telkom, Indonesia \\ Email: asepkaryana@student.telkomuniversity.ac.id
}

Received 2 Agustus 2019 | Revised 24 September 2019 | Accepted 5 November 2019

\begin{abstract}
ABSTRAK
Digital Video Broadcasting-Second Generation Terrestrial (DVB-T2) merupakan standar internasional yang menaungi pemberlakuan televisi digital saat ini. Pada konfigurasi DVB-T2 terdapat perangkat penerima sinyal di sisi pelanggan. Permasalahan yang sering dijumpai adalah lemahnya daya sinyal yang diterima. Oleh sebab itu, dibutuhkan penguat daya pada sistem penerima, yaitu Low Noise Amplifier (LNA) yang diletakkan setelah antena penerima. Pada penelitian ini, direalisasikan LNA menggunakan transistor BJT BFR96 dengan target desain dualstage, matching impedance Trafo $1 / 4$ pada sisi input dan output, serta lumped element untuk penyepadanan impedansi antar tingkat. LNA direalisasikan untuk bekerja optimal pada frekuensi $630 \mathrm{MHz}$. Nilai Gain dan Noise Figure (NF) yang diperoleh berturut-turut, yaitu $12.96 \mathrm{~dB}$ dan $4.05 \mathrm{~dB}$. Selain itu, nilai Voltage Standing Wave Ratio (VSWR) input dan output yang diperoleh berturut-turut sebesar 3.5674 dan 1.7718.
\end{abstract}

Kata kunci: DVB-T2, LNA, Televisi, Gain, Noise Figure

\begin{abstract}
Digital Video Broadcasting-Second Generation Terrestrial (DVB-T2) is the international standard that over shadows the current implementation of digital television. In the DVB-T2 configuration, there is a signal receiving device on the receiver side. The problem that is often encountered is the weak signal power received. Therefore, a power amplifier is needed in the receiving system, namely Low Noise Amplifier (LNA) which is placed after the receiving antenna. In this research, LNA was realized using a BJT BFR96 transistor with a dual-stage configuration design target, $1 / 4$ impedance matching transformer on the input and output sides, and a lumped element for interstage matching impedances. LNA is realized to work optimally at frequency of $630 \mathrm{MHz}$. The Gain and Noise Figure (NF) values obtained were $12.96 d B$ and $4.05 d B$, respectively. In addition, the input and output Voltage Standing Wave Ratio (VSWR) values obtained were 3.5674 and 1.7718 , respectively.
\end{abstract}

Keywords: DVB-T2, LNA, Television, Gain, Noise Figure 
Karyana, dkk

\section{PENDAHULUAN}

Televisi Digital adalah jenis televisi yang menggunakan modulasi digital dan sistem kompresi untuk mentransmisikan sinyal gambar, suara, dan data ke pesawat televisi. Penggunaan teknologi televisi digital di Indonesia telah ditetapkan oleh Kementerian Komunikasi dan Informasi (Kemkominfo) pada tahun 2011 (Surjati, Alam, \& Ningsih, 2019), yaitu untuk Digital Video Broadcasting-Terrestrial (DVB-T) dan dikembangkan menjadi Digital Video Broadcasting-Second Generation Terrestrial (DVB-T2) pada tahun 2012 (KOMINFO, 2012). DVB-T2 mengarah pada pengurangan spektrum yang dibutuhkan, jangkauan sinyal radio yang lebih baik, peningkatan kualitas gambar, serta kemampuan layanan interaktif. DVB-T2 didesain untuk beroperasi pada pita frekuensi IV dan V, yakni dengan rentang frekuensi $470-862 \mathrm{MHz}$ (Tsaraklimanis \& Karagianni, 2011).

Pada konfigurasi DVB-T2 terdapat perangkat penerima sinyal di sisi pelanggan. Permasalahan yang sering dijumpai pada semua perangkat penerima sinyal (receiver) adalah lemahnya daya sinyal yang diterima. Untuk mengatasi kendala tersebut dibutuhkan penguat daya pada sistem penerima, yaitu Low Noise Amplifier (LNA) yang diletakkan setelah antena penerima di sisi receiver. LNA digunakan untuk menguatkan sinyal dengan nilai noise yang tetap kecil (Wibisono, Firmansyah, \& Ma'arang, 2012). Maka untuk mencapai kondisi tersebut, pada penelitian ini LNA dirancang dual-stage agar gain menjadi lebih besar, sehingga memenuhi spesifikasi DVB-T2. LNA diharuskan mempunyai nilai gain yang besar dengan level noise yang seminimal mungkin. Hal ini berkaitan dengan Signal to Noise Ratio (SNR) yang akan semakin besar ketika nilai level sinyal input yang dihasilkan semakin besar. Ketika SNR semakin besar, maka performansi dari sistem komunikasi akan semakin baik. LNA haruslah dirancang multistage agar gain yang diperoleh menjadi lebih besar. Beberapa parameter penting yang harus diperhatikan pada sebuah proses perancangan LNA adalah faktor stabilitas (K), penguatan (gain), Noise Figure (NF), Direct Current(DC) biasing, dan Voltage Standing Wave Ratio (VSWR).

Penelitian mengenai perancangan LNA sudah banyak dilakukan oleh peneliti sebelumnya. Perolehan nilai gain yang tidak terlalu signifikan dengan metode single-stage amplifier telah dibuktikan oleh (Kim, 2014). Pada penelitian tersebut digunakan teknik penyesuai impedansi positive feedback dengan teknologi Complementary Metal-Oxide-Semiconductor(CMOS) 0.18 $\mu \mathrm{m}$. Hasil pengukuran menunjukkan perolehan nilai gain sebesar $12 \mathrm{~dB}$ dengan NF sebesar $6.4 \mathrm{~dB}$. Metode single-stage amplifier dengan teknik penyesuai impedansi yang berbeda juga diusulkan oleh (Misran, dkk., 2013). Pada penelitian tersebut, digunakan teknik penyesuai impedansi small inductances feedback and hybrid couplers balanced topology. Dari hasil pengukuran diperoleh nilai gain sebesar $10.024 \mathrm{~dB}$. Usulan (Raut \& Deshmukh, 2014) dengan metode dual-stage amplifier tetapi dengan teknik penyesuai impedansi yang berbeda juga telah dilakukan. Pada penelitian tersebut, digunakan teknik penyesuai impedansi inductive source degeneration topology cascaded stage di sisi input dan teknik LC tank circuit di sisi output. Hasil pengukuran menunjukkan nilai gain yang diperoleh sebesar $10.147 \mathrm{~dB}$. Selain itu, (Chang-Tsung Fu, Chien-Nan Kuo, \& Taylor, 2010) juga mengusulkan teknik lain dalam perancangan LNA guna diperoleh gain yang besar. Teknik yang dipakai yaitu dualfeedback shunt capacitive and series dengan teknologi CMOS $0.18 \mu \mathrm{m}$. Pada hasil pengukuran diperoleh nilai gain sebesar $11 \mathrm{~dB}$.

Penelitian ini bertujuan untuk meningkatkan nilai gain pada LNA yang dapat bekerja pada rentang frekuensi alokasi TV Digital yang ditetapkan, yaitu $470-790 \mathrm{MHz}$ dan optimal pada frekuensi tengahnya, yaitu $630 \mathrm{MHz}$. Hasil produk dari penelitian ini nantinya akan digunakan untuk riset TV Komunitas di Fakultas Ilmu Terapan Universitas Telkom. Cara yang dilakukan yaitu dengan merancang LNA dua tingkat menggunakan teknik penyesuai impedansi Trafo $\lambda / 4$ 
Realisasi LNA Dua Tingkat dengan Teknik Penyesuai Impedansi Trafo $\lambda / 4$ dan Lumped Element untuk DVB-T2

dan lumped element. Teknik penyesuai impedansi tersebut dipilih karena kemudahan dalam tuning dan perealisasiannya. Transistor yang digunakan untuk merancang LNA yaitu transistor BJT BFR96 dengan menggunakan substrat FR4 Epoxy. Berdasarkan analisis datasheet transistor dan penelitian oleh (Tsaraklimanis \& Karagianni, 2011), LNA yang dirancang diharapkan mempunyai spesifikasi gain $>10 \mathrm{~dB}, \mathrm{NF}<5 \mathrm{~dB}$, VSWR input dan output $<2$, serta $\mathrm{K}$ yang bernilai $>1$ atau Unconditionally Stable.

\section{DESAIN LOW NOISE AMPLIFIER (LNA)}

\subsection{Metode dan Alur Perancangan}

Pada penelitian ini, LNA direalisasikan dengan konfigurasi dual-stage amplifier. Hal ini dilakukan agar diperoleh nilai gain yang besar (Taryana et al., 2015). Selain itu, digunakan juga teknik matching impedance Trafo $\lambda / 4$ di sisi input dan output, serta lumped element berupa seri kapasitor pada penyepadanan impedansi antar tingkatnya. Rangkaian prategangan/ biasing yang digunakan adalah tipe self-biasing collector feedback. Tipe ini dipilih karena hanya membutuhkan dua resistor dalam perancangannya, sehingga mempermudah perealisasian. Jenis substrat yang digunakan adalah FR-4 Epoxy. Penggunaan substrat ini dimaksudkan agar LNA mempunyai dimensi yang kecil karena FR-4 Epoxy memiliki nilai konstanta dielektrik $\left(\varepsilon_{r}\right)$ yang besar, yaitu 4.6 dengan ketebalan $(h)$ sebesar $1.6 \mathrm{~mm}$. Selain itu, jenis substrat ini juga mudah ditemukan di pasaran dengan harga yang relatif terjangkau.

Perealisasian diawali dengan perancangan rangkaian prategangan dengan memilih titik kerja transistor. Titik kerja transistor yang dipilih merupakan hasil analisis karakteristik transistor yang terdapat pada datasheet (Motorola Inc., 1994) berdasarkan pengaplikasian LNA yang dimaksud. Berikut merupakan titik kerja transistor yang dipilih pada penelitian kali ini.

Tabel 1. Parameter Titik Kerja Transistor

\begin{tabular}{|c|c|c|}
\hline Nama Parameter & Simbol & Nilai \\
\hline Arus Collector & $I_{C}$ & $25 \mathrm{~mA}$ \\
\hline Penguatan Arus DC & $h_{F E}$ & 100 \\
\hline Tegangan Collector-Emitter & $V_{C E}$ & $6 \mathrm{~V}$ \\
\hline Tegangan Base-Emitter & $V_{B E}$ & $0.7 \mathrm{~V}$ (Silikon) \\
\hline Tegangan Catu DC & $V_{C C}$ & $12 \mathrm{~V}$ \\
\hline
\end{tabular}

Parameter titik kerja transistor digunakan untuk menghitung nilai komponen yang digunakan pada rangkaian prategangan. Setelah nilai komponen didapat, langkah selanjutnya yaitu menyimulasikannya untuk diperoleh nilai kestabilan transistor (K) dan Parameters S. Nilai Parameter S inilah yang akan digunakan untuk menentukan koefisien pantul sumber dan beban. Setelah nilai koefisien pantul didapat, maka Impedance Matching Circuit (IMC) dapat diperoleh.

Flowchart perancangan dan realisasi LNA dapat dilihat pada Gambar 1. 

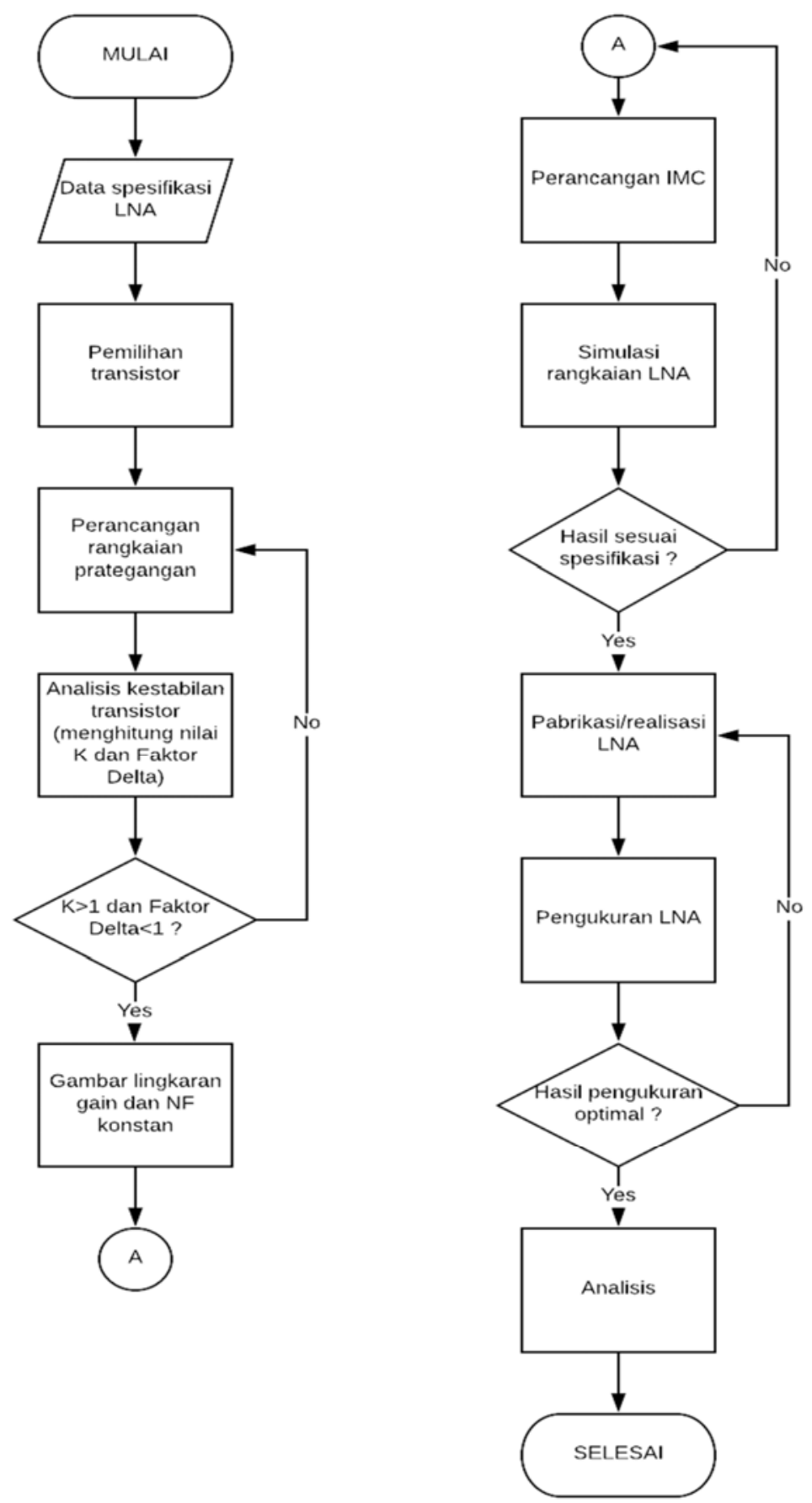

Gambar 1. Flowchart Perancangan dan Realisasi LNA

\subsection{Tahapan Perancangan}

Parameter S digunakan untuk menentukan stabilitas/kemantapan suatu transistor. Oleh karena tidak tercantumnya parameter S pada datasheetBFR96 pada frekuensi $630 \mathrm{MHz}$, maka nilai parameter $\mathrm{S}$ didapat dari hasil simulasi pada software ADS. 
Realisasi LNA Dua Tingkat dengan Teknik Penyesuai Impedansi Trafo $\lambda / 4$ dan Lumped Element untuk DVB-T2

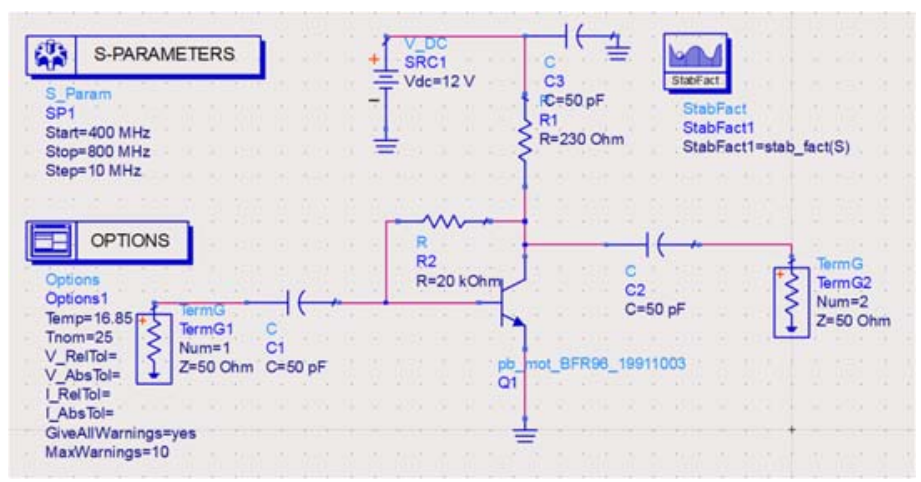

Gambar 2. Rangkaian Prategangan
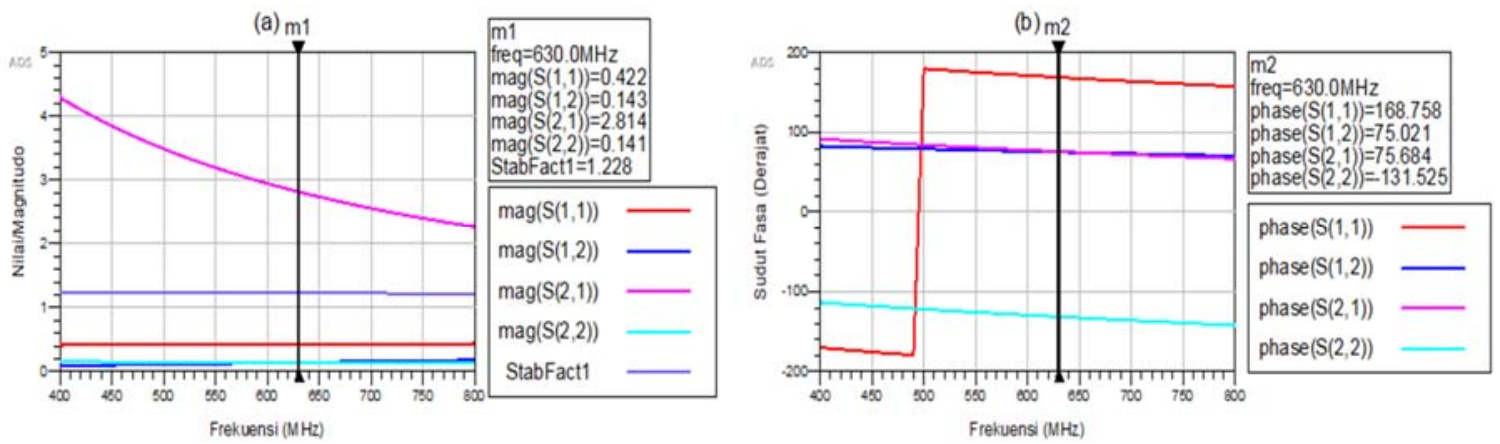

Gambar 3. Hasil Simulasi (a) Magnitudo Parameter S dan K; (b) Sudut Fasa Parameter S

Ketika nilai K > 1, maka transistor dapat dikatakan stabil tak bersyarat (unconditionally stable). Penentuan koefisien pantul merupakan hal penting dalam merancang suatu LNA. Agar tercapai kondisi Simultaneous Conjugate Match, maka koefisien pantul sumber dan beban diperoleh menggunakan persamaan (Pozar, 1998)

$$
\begin{aligned}
& \Gamma_{S}=\Gamma_{S M}=\frac{B_{1} \pm \sqrt{B_{1}{ }^{2}-4\left|C_{1}\right|^{2}}}{2 C_{1}}, \\
& \Gamma_{L}=\Gamma_{L M}=\frac{B_{2} \pm \sqrt{B_{2}{ }^{2}-4\left|C_{2}\right|^{2}}}{2 C_{2}}, \\
& B_{1}=1+\left|S_{11}\right|^{2}-\left|S_{22}\right|^{2}-|\Delta|^{2}, \\
& B_{2}=1+\left|S_{22}\right|^{2}-\left|S_{11}\right|^{2}-|\Delta|^{2},
\end{aligned}
$$

dengan $\Gamma_{S}$ adalah koefisien pantul sumber, $\Gamma_{L}$ adalah koefisien pantul beban, $S_{11}$ adalah sinyal yang dipantulkan kembali ke port 1 , dan $S_{22}$ adalah sinyal yang dipantulkan kembali ke port 2. Terlihat pada Gambar 3, nilai $S_{11}$ dan $S_{22}$ diperoleh berturut-turut sebesar $0.422 \angle 168.758^{\circ}$ dan $0.141 \angle-131.525^{\circ}$. Setelah proses perhitungan dilakukan, maka didapat nilai $\Gamma_{S}=0.51 \angle-$ $176.369^{\circ}$ dan $\Gamma_{L}=0.262 \angle 58.855^{\circ}$.

Penyepadanan impedansi menggunakan Trafo $\lambda / 4$ yaitu melakukan penambahan saluran sepanjang $\lambda / 4$ diantara saluran transmisi utama dan beban dengan impedansi Trafo $\left(Z_{T}\right)$. Nilai impedansi input ternormalisasi $Z_{N I n}$ diperoleh dengan memutar impedansi beban ternormalisasi $Z_{N L}$ sepanjang $d_{R}$ sampai menyentuh garis bilangan riil pada Smith Chart 
(Iskander, 2012). Visualisasi dari pernyataan di atas dapat dilihat pada Gambar 4 di bawah ini.

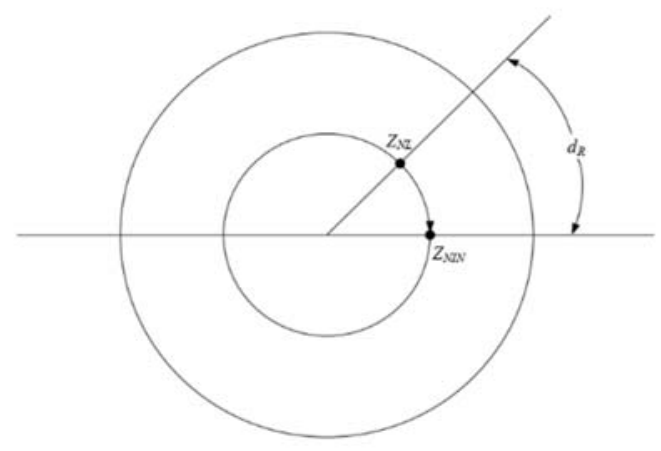

Gambar 4. Proses Penyepadanan Impedansi Trafo $\lambda / 4$

Setelah itu, Trafo $\lambda / 4$ dimasukkan diantara saluran transmisi utama dan saluran transmisi input seperti yang tersaji pada Gambar 5 dengan persamaan impedansi Trafo, yaitu:

$$
\begin{aligned}
& Z_{T}=\sqrt{Z_{O} Z_{\text {In }}} \\
& Z_{\text {In }}=Z_{O} Z_{\text {NIn }}
\end{aligned}
$$

dengan $Z_{T}$ adalah impedansi Trafo, $Z_{O}$ adalah impedansi karakteristik, $Z_{I n}$ adalah impedansi input, dan $Z_{N I n}$ adalah impedansi input ternormalisasi. Pada Gambar $5, Z_{L}$ merupakan impedansi beban dan $d_{R}$ merupakan panjang saluran transmisi utama. Selain penyepadanan impedansi menggunakan Trafo $\lambda / 4$, pada penelitian ini juga digunakan teknik penyepadanan impedansi menggunakan /umped element. Penyepadanan impedansi menggunakan /umped element yaitu penyepadanan dengan cara menambahkan komponen pasif kedalam saluran transmisi. Penentuan komponen dan harganya dapat dilakukan dengan prosedur Smith Chart.

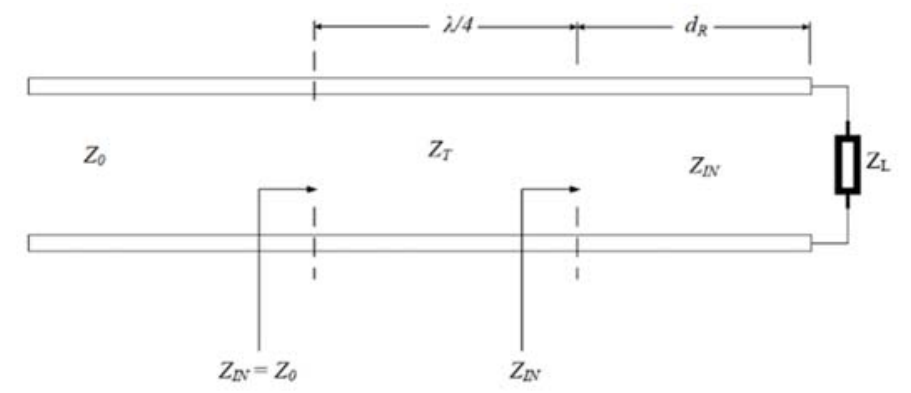

Gambar 5. Penyepadanan Impedansi Trafo $\lambda / 4$ (Beban Bernilai Kompleks)

Selanjutnya yaitu perhitungan dimensi saluran mikrostrip. Tahapan dalam menentukan dimensi saluran mikrostrip adalah sebagai berikut (Chang, 2000).

Untuk strip sempit (ketika $Z_{o}>44-2 \varepsilon_{r}$ ), maka

$$
\begin{gathered}
\frac{W}{h}=\left(\frac{e^{H^{\prime}}}{8}-\frac{1}{4 e^{H^{\prime}}}\right)^{-1}, \\
H^{\prime}=\frac{Z_{0} \sqrt{2\left(\varepsilon_{r}+1\right)}}{119.9}+\frac{1}{2}\left(\frac{\varepsilon_{r}-1}{\varepsilon_{r}+1}\right)\left(\ln \frac{\pi}{2}+\frac{1}{\varepsilon_{r}} \ln \frac{4}{\pi}\right),
\end{gathered}
$$


Realisasi LNA Dua Tingkat dengan Teknik Penyesuai Impedansi Trafo $\lambda / 4$ dan Lumped Element untuk DVB-T2

dengan $W$ adalah lebar mikrostrip, $h$ adalah tebal substrat, dan $\varepsilon_{r}$ adalah konstanta dielektrik bahan substrat.

Untuk strip lebar (ketika $Z_{o}<44-2 \varepsilon_{r}$ ), maka

$$
\begin{gathered}
\frac{W}{h}=\frac{2}{\pi}\left\{\left(d_{\varepsilon}-1\right)-\ln \left(2 d_{\varepsilon}-1\right)\right\}+\frac{\varepsilon_{r}-1}{\pi \varepsilon_{r}}\left\{\ln \left(d_{\varepsilon}-1\right)+0.293-\frac{0.517}{\varepsilon_{r}}\right\} \\
d_{\varepsilon}=\frac{59.95 \pi^{2}}{Z_{o} \sqrt{\varepsilon_{r}}}
\end{gathered}
$$

Panjang gelombang dari saluran mikrostrip dinyatakan sebagai berikut:

Untuk $\frac{W}{h} \geq 0.6$;

Untuk $\frac{W}{h}<0.6$;

$$
\lambda=\frac{\lambda_{o}}{\sqrt{\varepsilon_{r}}}\left[\frac{\varepsilon_{r}}{1+0.63\left(\varepsilon_{r}-1\right)\left(\frac{W}{h}\right)^{0.1255}}\right]^{1 / 2},
$$

$$
\lambda=\frac{\lambda_{o}}{\sqrt{\varepsilon_{r}}}\left[\frac{\varepsilon_{r}}{1+0.6\left(\varepsilon_{r}-1\right)\left(\frac{W}{h}\right)^{0.0297}}\right]^{1 / 2},
$$

dengan $\lambda$ adalah panjang gelombang saluran mikrostrip dan $\lambda_{o}$ adalah panjang gelombang di udara bebas.

Dengan menggunakan Persamaan (7) sampai Persamaan (13), didapatlah nilai-nilai parameter

\begin{tabular}{|c|c|}
\hline Parameter & Nilai \\
\hline \multicolumn{2}{|c|}{ Input $\left(Z_{\text {In }}=16.25 \Omega, Z_{T}=28.504 \Omega\right)$} \\
\hline$W_{\text {Saluran }}$ & $13.88 \mathrm{~mm}$ \\
\hline$l_{\text {Saluran }}$ & $1.195 \mathrm{~mm}$ \\
\hline$W_{\text {Trafo }}$ & $6.803 \mathrm{~mm}$ \\
\hline$l_{\text {Trafo }}$ & $61.75 \mathrm{~mm}$ \\
\hline \multicolumn{2}{|l|}{ Interstage } \\
\hline$W_{\text {Saluran }}$ & $2.903 \mathrm{~mm}$ \\
\hline$l_{\text {Saluran }}$ & $46.819 \mathrm{~mm}$ \\
\hline C & $7.289 \mathrm{pF}$ \\
\hline \multicolumn{2}{|c|}{ Output $\left(Z_{I n}=29.5 \Omega, Z_{T}=38.406 \Omega\right)$} \\
\hline$W_{\text {Saluran }}$ & $6.491 \mathrm{~mm}$ \\
\hline$l_{\text {Saluran }}$ & $41.496 \mathrm{~mm}$ \\
\hline$W_{\text {Trafo }}$ & $4.494 \mathrm{~mm}$ \\
\hline$l_{\text {Trafo }}$ & $62.75 \mathrm{~mm}$ \\
\hline
\end{tabular}
seperti yang tersaji pada Tabel 2. Pada penyepadanan impedansi interstage digunakan tools Smith Chart Utility dan Line Calculator agar mempermudah perancangan.

Tabel 2. Nilai Parameter Hasil Perhitungan 


\section{HASIL PERANCANGAN DAN PEREALISASIAN}

\subsection{Simulasi Desain LNA}

Setelah semua dimensi mikrostrip diketahui, langkah selanjutnya adalah menyimulasikan seluruh rangkaian yang sudah dibuat. Tujuan simulasi ini adalah untuk mengetahui apakah LNA sudah sesuai dengan spesifikasi awal perancangan atau belum. Gambar 6 merupakan desain skematik rangkaian LNA dua tingkat yang dibuat.



Gambar 6. Desain Skematik LNA
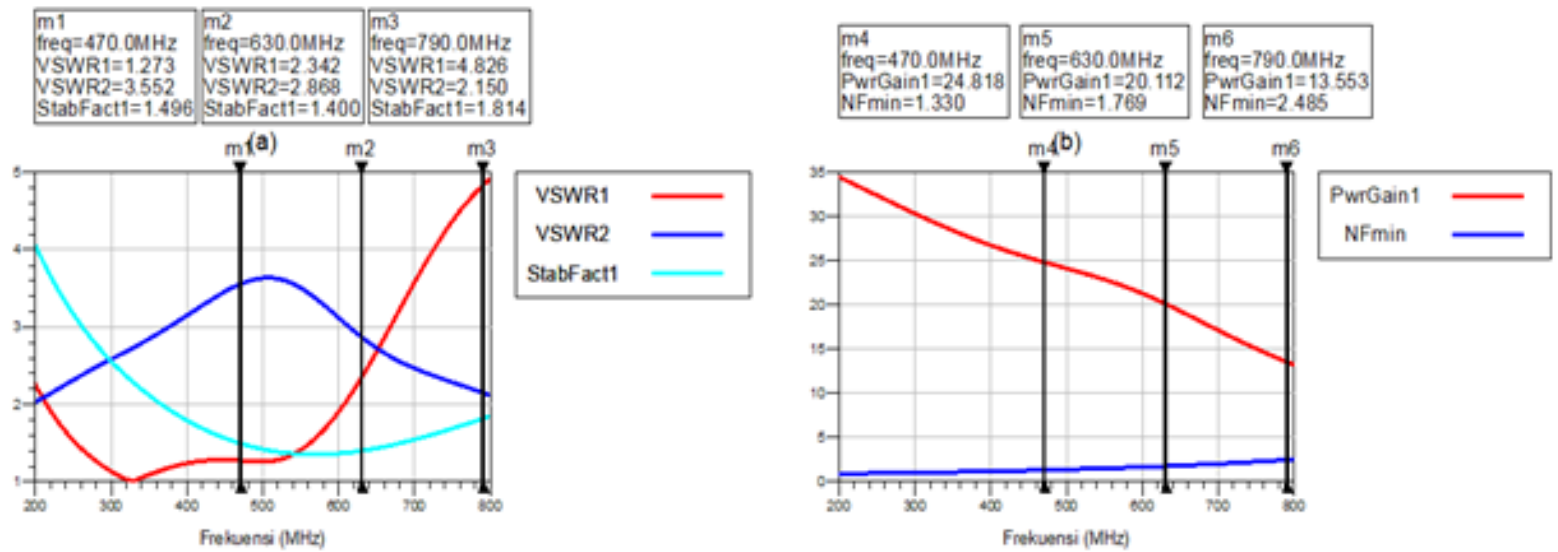

Gambar 7. Hasil Simulasi Desain LNA (a) VSWR dan K; (b) NF dan Gain

Pada Gambar 7, dihasilkan simulasi dari beberapa parameter LNA. NF pada frekuensi $630 \mathrm{MHz}$ bernilai $1.769 \mathrm{~dB}$. Nilai ini sudah sesuai dengan spesifikasi awal LNA, yaitu $<5 \mathrm{~dB}$. Gain pada frekuensi $63 \mathrm{OMHz}$ bernilai $20.112 \mathrm{~dB}$. Nilai ini sudah sesuai dengan spesifikasi awal LNA, yaitu $>10 \mathrm{~dB}$. Stability factor pada frekuensi $630 \mathrm{MHz}$ bernilai 1.4. Nilai ini sudah sesuai dengan spesifikasi awal, yaitu $>1$ (Unconditionally Stable). VSWR input $\left(V S W R_{1}\right)$ dan VSWR output $\left(V S W R_{2}\right)$ pada frekuensi $630 \mathrm{MHz}$ berturut-turut bernilai 2.342 dan 2.868. Nilai VSWR input dan output masih belum sesuai dengan spesifikasi awal LNA, yaitu $<2$. 
Realisasi LNA Dua Tingkat dengan Teknik Penyesuai Impedansi Trafo $\lambda / 4$ dan Lumped Element untuk DVB-T2

\subsection{Optimasi Desain LNA}

Optimasi dilakukan untuk memperbaiki nilai parameter LNA yang belum baik dan tidak sesuai dengan spesifikasi perancangan. Parameter yang belum sesuai dengan spesifikasi LNA pada perancangan kali ini adalah VSWR. Optimasi dilakukan dengan perhitungan ulang dan dilanjutkan dengan mengubah-ubah/mengatur nilai dimensi saluran mikrostrip (tuning) pada software ADS. Tuning dilakukan dengan metode trial and error dengan tetap memperhatikan dimensi hasil perhitungan agar tidak melenceng terlalu jauh.

Tabel 3. Perubahan Nilai Parameter

\begin{tabular}{|c|c|c|}
\hline \multirow[b]{2}{*}{ Parameter } & \multicolumn{2}{|c|}{ Dimensi (mm) } \\
\hline & $\begin{array}{l}\text { Sebelum } \\
\text { Optimasi }\end{array}$ & $\begin{array}{l}\text { Setelah } \\
\text { Optimasi }\end{array}$ \\
\hline \multicolumn{3}{|l|}{ Input } \\
\hline$W_{\text {Saluran }}$ & 13.88 & 0 \\
\hline$l_{\text {Saluran }}$ & 1.195 & 0 \\
\hline$W_{\text {Trafo }}$ & 6.803 & 10.204 \\
\hline$l_{\text {Trafo }}$ & 61.75 & 40.137 \\
\hline \multicolumn{3}{|l|}{ Interstage } \\
\hline$W_{\text {Saluran }}$ & 2.903 & 2.903 \\
\hline$l_{\text {Saluran }}$ & 46.819 & 45.414 \\
\hline \multicolumn{3}{|l|}{ Output } \\
\hline$W_{\text {Saluran }}$ & 6.491 & 3.245 \\
\hline$l_{\text {Saluran }}$ & 41.496 & 61.829 \\
\hline$W_{\text {Trafo }}$ & 4.494 & 6.741 \\
\hline$l_{\text {Trafo }}$ & 62.75 & 37.002 \\
\hline
\end{tabular}

Dimensi saluran input sengaja ditiadakan karena berdasarkan simulasi pada ADS, ada atau tidak adanya stripline tersebut tidak mempengaruhi hasil simulasi. Langkah ini diambil juga guna memperkecil dimensi LNA yang akan direalisasikan. Setelah optimasi, maka desain disimulasikan lagi sebagaimana ditunjukkan pada Gambar 8.

Gambar 8 menunjukkan desain skematik rangkaian sesudah tuning. Gambar 9 menunjukkan hasil simulasi dari beberapa parameter LNA setelah dilakukan tuning. NF pada frekuensi 630 $\mathrm{MHz}$ bernilai $1.532 \mathrm{~dB}$ dan nilainya turun dari hasil simulasi sebelum tuning. Nilai ini sudah sesuai dengan spesifikasi awal LNA, yaitu $<5 \mathrm{~dB}$. Gain pada frekuensi $630 \mathrm{MHz}$ naik menjadi $22.772 \mathrm{~dB}$. Nilai ini sudah sesuai dengan spesifikasi awal LNA, yaitu $>10 \mathrm{~dB}$. Stability factor pada frekuensi $630 \mathrm{MHz}$ bernilai 1.269. Nilai ini sudah sesuai dengan spesifikasi awal, yaitu > 1 (Unconditionally Stable). VSWR input $\left(\mathrm{VSWR}_{1}\right)$ dan VSWR output (VSWR $\mathrm{V}_{2}$ ) pada frekuensi $630 \mathrm{MHz}$ berturut-turut bernilai 1.118 dan 1.148 . Nilai keduanya kali ini sudah sesuai dengan spesifikasi awal LNA, yaitu $<2$.

Ketika semua nilai parameter sudah sesuai dengan spesifikasi awal, maka tahap selanjutnya adalah perealisasian/pabrikasi LNA. Untuk mendapatkan desain layout PCB dari skematik LNA yang telah dibuat, pada penelitian ini digunakan software Altium Designer untuk mempermudah realisasinya. Tampilan layout LNA yang akan digunakan untuk proses realisasi/pabrikasi tersaji pada Gambar 10. 


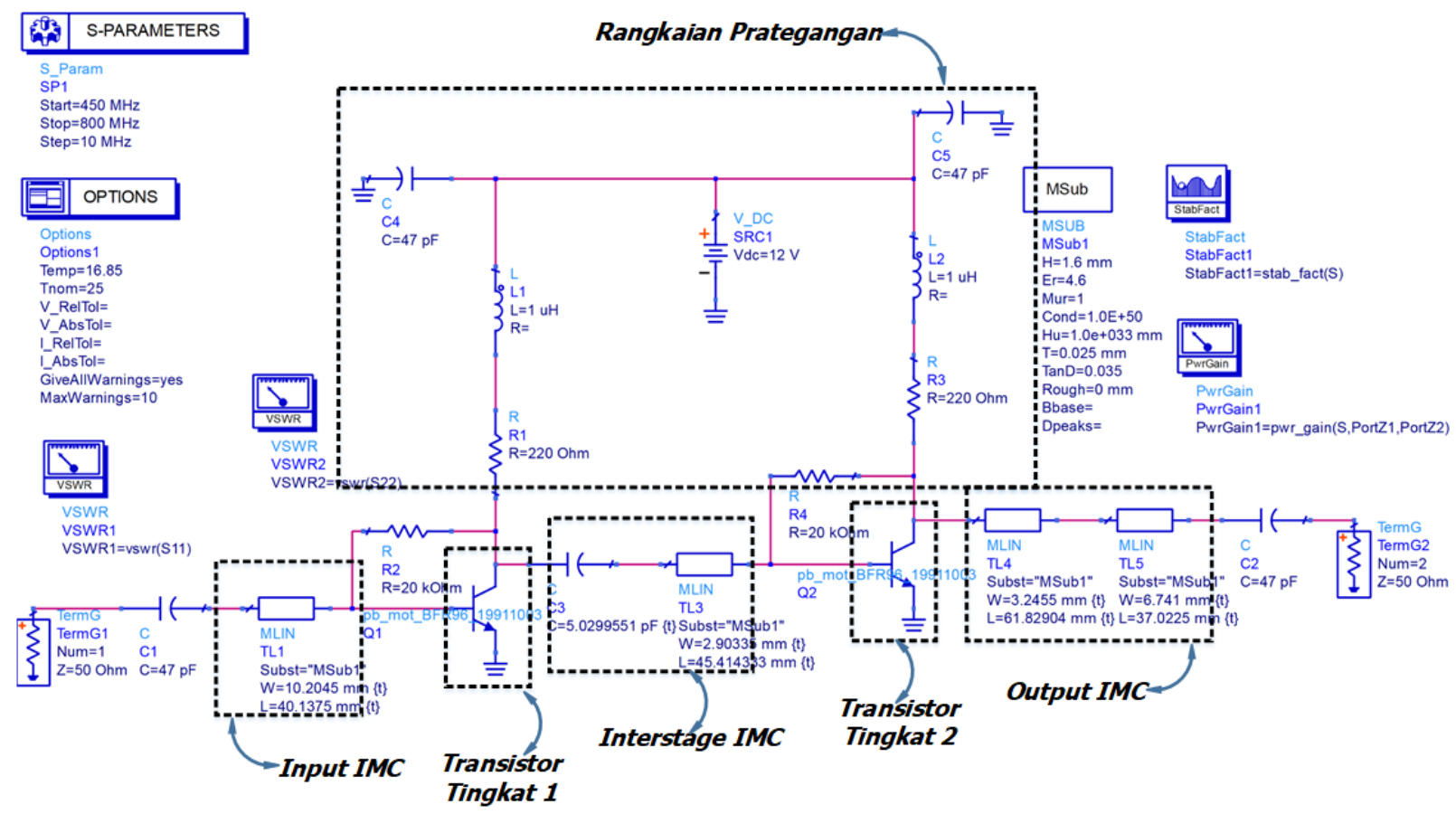

Gambar 8. Desain Skematik LNA Setelah Optimasi
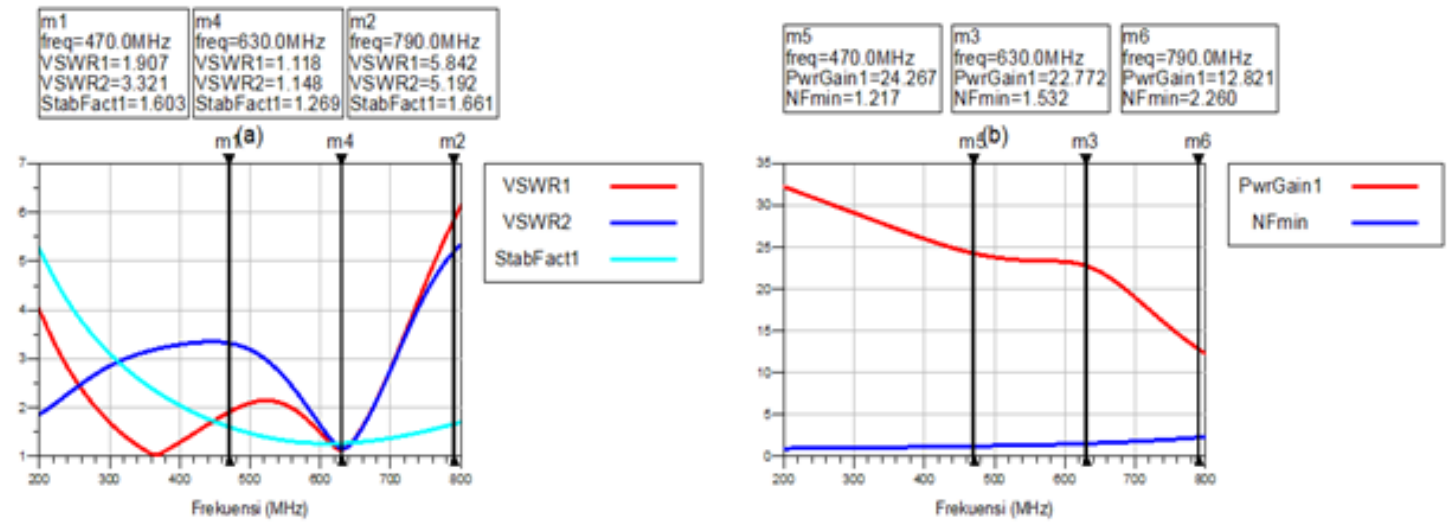

Gambar 9. Hasil Simulasi Desain LNA Setelah Optimasi (a) VSWR dan K; (b) NF dan Gain

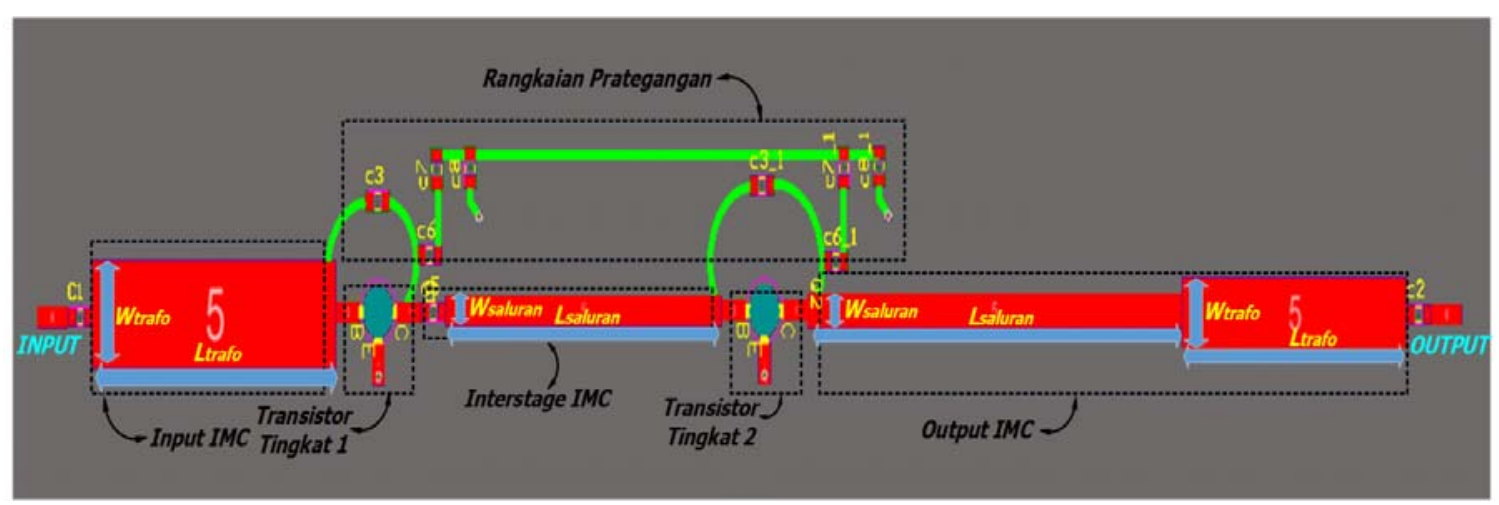

Gambar 10. Tampilan Layout LNA 


\subsection{Realisasi LNA}

Setelah hasil simulasi parameter sesuai dengan spesifikasi awal, maka langkah selanjutnya adalah melakukan realisasi/pabrikasi LNA kedalam bentuk PCB. Realisasi/pabrikasi dilakukan dengan bantuan jasa percetakan PCB dengan mengirimkan file desain layout PCB. Berikut Gambar 11 dan Gambar 12 menunjukkan tampilan realisasi dari LNA.

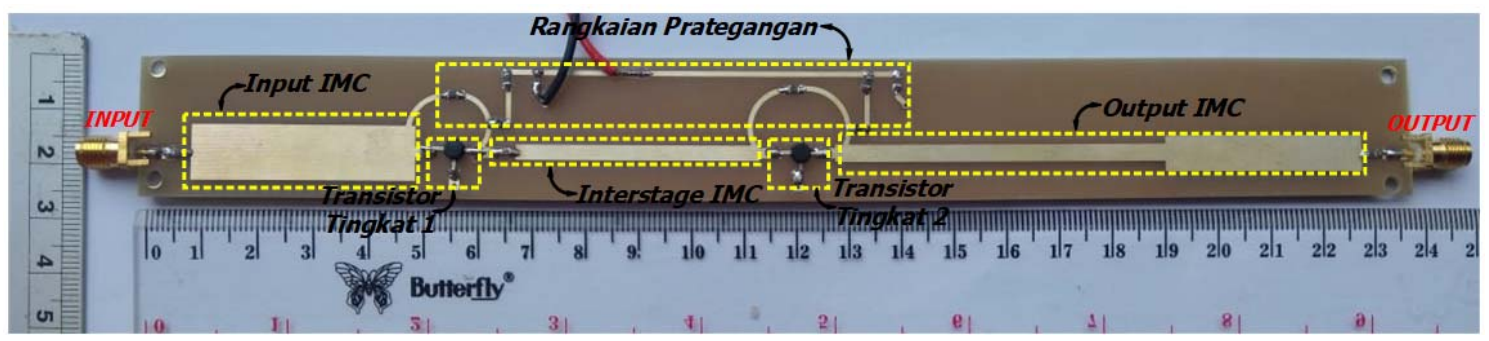

Gambar 11. Tampilan Depan LNA Hasil Realisasi

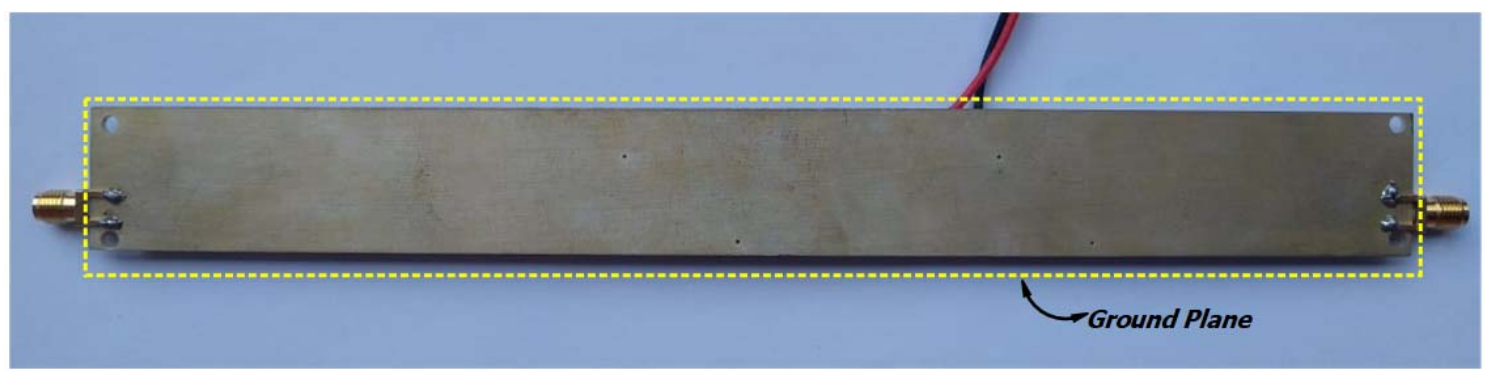

Gambar 12. Tampilan Belakang LNA Hasil Realisasi

Gambar 11 memperlihatkan tampilan LNA pada top layer, yakni tempat komponen dan stripline penyepadan impedansi diletakkan. Sementara itu, Gambar 12 memperlihatkan tampilan LNA pada bottom layer, yakni sebagai bidang groundplane LNA tersebut. Terminal-terminal ground pada top layer juga dihubungkan dengan groundplane menggunakan through hole.

\subsection{Hasil Pengukuran LNA}

Pengukuran VSWR dilakukan dengan menggunakan Vector Network Analayzer (VNA) merek Transcom Instruments tipe T5280A (200 kHz - $5 \mathrm{GHz}$ ), sedangkan pengukuran Gain dan NF dilakukan dengan menggunakan Spectrum Analyzer (SA) merek Rigol tipe DSA875 (9 kHz $7.5 \mathrm{GHz}$ ). Pengukuran dilakukan di Wireless Communication Laboratory D3 Teknologi Telekomunikasi Fakultas Ilmu Terapan Universitas Telkom Bandung. Set-up pengukuran LNA ditunjukkan oleh Gambar 13, Gambar 14, dan Gambar 15. Sementara itu, hasil pengukuran Gain dan VSWR dari LNA yang diusulkan dapat dilihat pada Gambar 16, Gambar 17, dan Gambar 18.

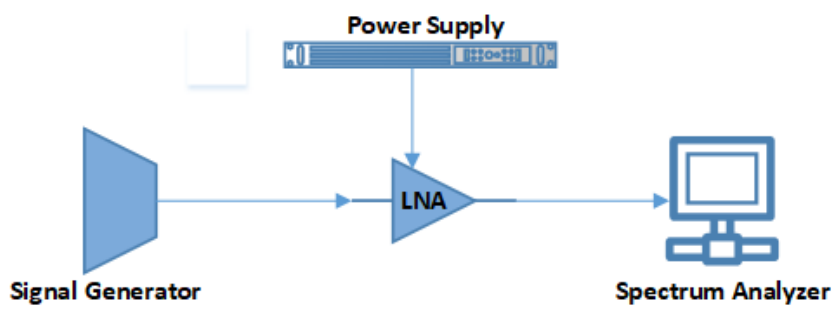

Gambar 13. Set-up Pengukuran Gain 


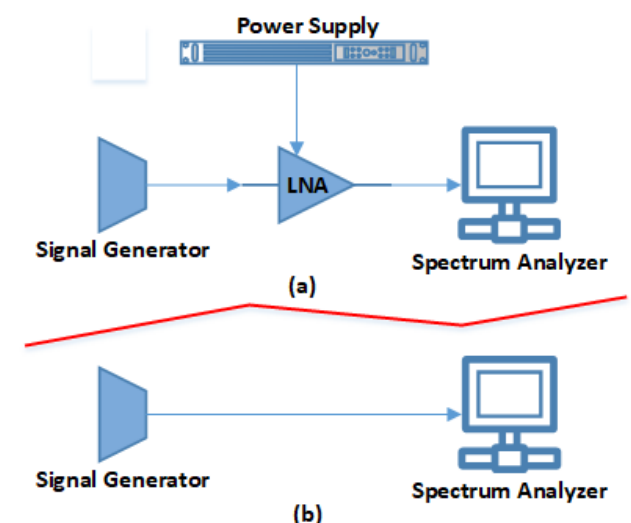

Gambar 14. Set-up Pengukuran NF

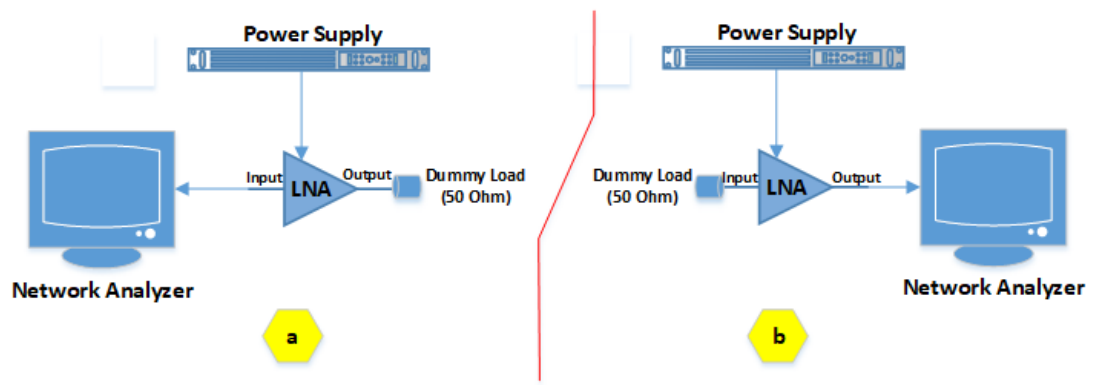

Gambar 13. Set-up Pengukuran VSWR

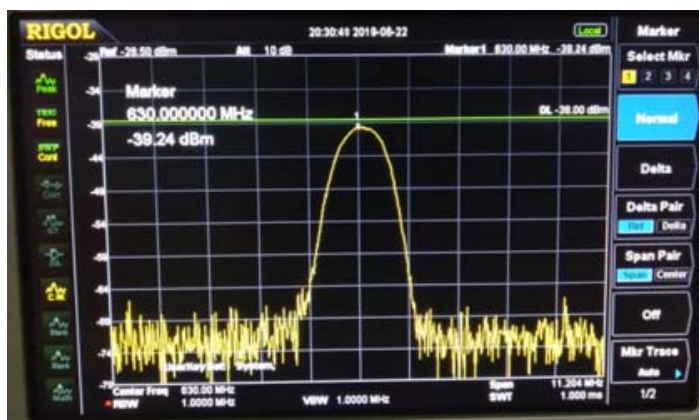

Gambar 16. Hasil Pengukuran Gain Output Pada Frekuensi 630MHz Dengan Level Daya Input -50dBm

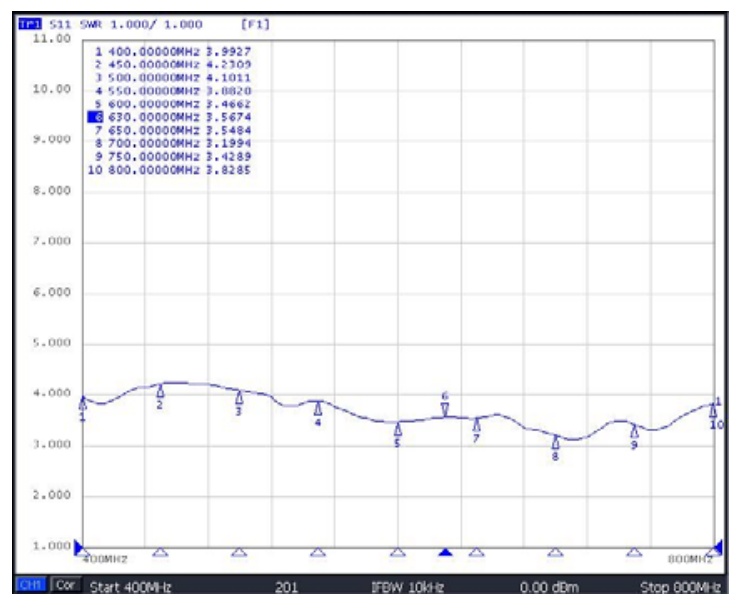

Gambar 17. Hasil Pengukuran VSWR Input

ELKOMIKA - 12 


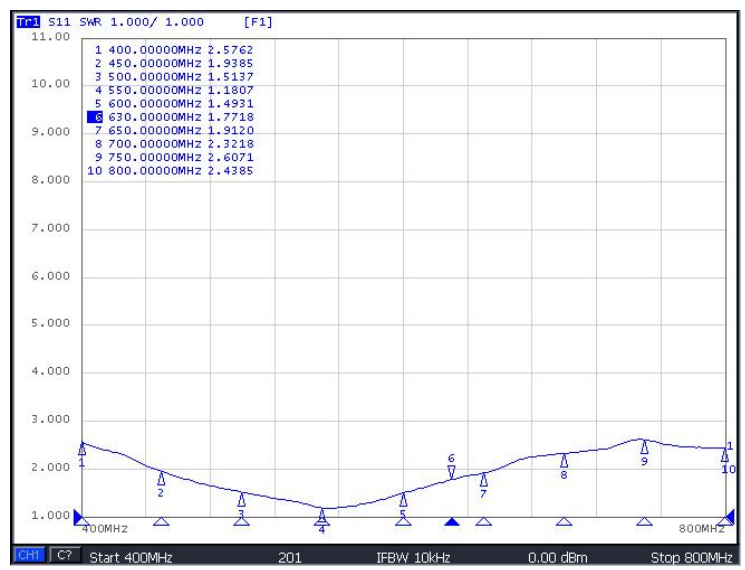

Gambar 18. Hasil Pengukuran VSWR Output

Pada Gambar 18, terlihat bahwa level daya output LNA bernilai $-39.24 \mathrm{dBm}$ ketika diberikan level daya input sebesar $-50 \mathrm{dBm}$. Dari data level daya output tersebut, nilai gain dapat diperoleh dengan Persamaan (14) (Djalil, Budianto, \& Sumajudin, 2011):

$$
\operatorname{Gain}(d B)=P_{\text {out }}-P_{\text {In }}+\text { Cable Loss, }
$$

dengan $P_{\text {out }}$ adalah daya keluaran dan $P_{I n}$ adalah daya masukan. Pada pengukuran ini, harga Cable Loss sebesar $2.2 \mathrm{~dB}$. Sehingga, gain yang diperoleh adalah sebesar $12.96 \mathrm{~dB}$. Nilai ini sudah sesuai dengan spesifikasi awal LNA, yaitu $>10 \mathrm{~dB}$.

Pada Gambar 14 dan Gambar 15, terlihat bahwa perolehan VSWR input dan output pada frekuensi $630 \mathrm{MHz}$ berturut-turut, yaitu sebesar 3.5674 dan 1.7718. Nilai VSWR input masih belum sesuai dengan spesifikasi awal LNA. Hal ini bisa disebabkan karena dimensi stripline yang terlalu besar sehingga mudah untuk terinterferensi oleh sinyal yang lain. Sementara itu, nilai VSWR output sudah sesuai dengan spesifikasi awal LNA, yaitu $<2$.

Pengukuran NF dilakukan dengan metode Signal Input to Noise Ratio (SINR). Metode ini berkonsep pada perhitungan selisih antara SINR output $\left(\operatorname{SINR}_{\text {out }}\right)$ dan SINR input $\left(\operatorname{SINR}_{I n}\right)$. Variabel yang perlu dicari adalah $P_{\text {Out }}, N_{\text {Out }}, P_{I n}$, dan $N_{\text {In }}$. $P_{\text {Out }}$ yaitu level daya output yang tampil pada Spectrum Analyzer ketika LNA terpasang. $N_{\text {Out }}$ yaitu noise output yang terbaca pada Spectrum Analyzer ketika LNA terpasang. $P_{I n}$ yaitu level daya input yang tampil pada Spectrum Analyzer ketika LNA dilepaskan. $N_{\text {In }}$ yaitu noise input yang terbaca pada Spectrum Analyzer ketika LNA dilepaskan. Adapun nilai variabel yang terukur adalah sebagai berikut:

Tabel 4. Nilai Variabel Untuk Penentuan NF

\begin{tabular}{|c|c|c|c|}
\hline \multicolumn{4}{|c|}{ Nama Variabel } \\
\hline$P_{\text {Out }}$ & $N_{\text {Out }}$ & $P_{\text {In }}$ & $N_{\text {In }}$ \\
\hline$-39.24 \mathrm{dBm}$ & $-59.38 \mathrm{dBm}$ & $-50 \mathrm{dBm}$ & $-74.19 \mathrm{dBm}$ \\
\hline
\end{tabular}

Untuk memperoleh NF, maka dilakukan perhitungan sebagai berikut (Lestari, Endroyono, \& Hendrantoro, 2012).

$$
\begin{gathered}
N F=S I N R_{\text {In }}-\text { SINR }_{\text {Out }}, \\
N F=\left[\left(P_{\text {In }}-N_{\text {In }}\right)-\left(P_{\text {Out }}-N_{\text {Out }}\right)\right] \\
N F=[(-50+74.19)-(-39.24+59.38)] \\
N F=[(24.19)-(20.14)] \\
N F=4.05 d B
\end{gathered}
$$


Pada hasil perhitungan di atas, terlihat bahwa perolehan NF yaitu sebesar $4.05 \mathrm{~dB}$. Nilai ini sudah sesuai dengan spesifikasi awal LNA, yaitu $<5 \mathrm{~dB}$.

\subsection{Analisis Perbandingan Hasil Simulasi dan Pengukuran}

Perbandingan hasil simulasi parameter LNA dengan hasil pengukurannya pada frekuensi 630 $\mathrm{MHz}$ disajikan dalam Tabel 5 di bawah ini.

Tabel 5. Perbandingan Nilai Parameter LNA

\begin{tabular}{|c|c|c|c|}
\hline N Eksperimen & NF (dB) & Gain (dB) & VSWR Input dan Output \\
\hline N1 & 1.769 & 20.112 & 2.342 dan 2.868 \\
\hline N2 & 1.541 & 22.772 & 1.075 dan 1.175 \\
\hline N3 & 1.532 & 22.772 & 1.118 dan 1.148 \\
\hline N4 & $\mathbf{4 . 0 5}$ & $\mathbf{1 2 . 9 6}$ & $\mathbf{3 . 5 6 7 4}$ dan 1.7718 \\
\hline
\end{tabular}

Merujuk pada Tabel 5, N1, N2, N3, dan N4 berturut-turut merupakan simulasi hasil perhitungan awal, optimasi perhitungan ulang, optimasi dengan meniadakan stripline saluran utama input, dan realisasi. Tabel 5 juga memperlihatkan bahwa parameter pada $\mathrm{N} 4$ yang belum memenuhi spesifikasi awal perancangan adalah VSWR Input. Nilai VSWR Input masih $>2$, yaitu 3.5674. Hal ini bisa terjadi karena kesalahan dalam perhitungan sehingga dimensi stripline inputtidak dapat menyepadankan rangkaian LNA. Kekurangan ini akan menjadi bahan evaluasi untuk penelitian selanjutnya. Akan tetapi, dari hasil pengukuran secara keseluruhan dapat disimpulkan bahwa LNA sudah memenuhi spesifikasi utamanya, yaitu Gain dan NF yang baik. Maka dari itu, LNA yang diusulkan sudah layak untuk digunakan pada aplikasi DVB-T2.

\section{KESIMPULAN}

Penelitian ini telah berhasil merancang dan merealisasikan sebuah LNA untuk penerapan pada DVB-T2 dengan frekuensi $630 \mathrm{MHz}$. Dari hasil pengukuran setelah dilakukan beberapa kali optimasi, maka diperoleh nilai Gain sebesar $12.96 \mathrm{~dB}$, NF sebesar $4.05 \mathrm{~dB}$, serta VSWR Input dan Output berturut-turut sebesar 3.5674 dan 1.7718. Nilai-nilai dari parameter tersebut sudah sesuai dengan spesifikasi yang telah ditentukan, kecuali untuk nilai VSWR Input. Dari keseluruhan proses simulasi dan pengukuran dapat disimpulkan bahwa LNA yang realisasikan telah memenuhi kriteria dan cocok untuk digunakan pada aplikasi DVB-T2. Untuk penelitian selanjutnya, akan dilakukan field measurement ketika infrastruktur TV Komunitas telah berhasil dibangun.

\section{DAFTAR RUJUKAN}

Chang-Tsung Fu, Chien-Nan Kuo, \& Taylor, S. S. (2010). Low-Noise Amplifier Design With Dual Reactive Feedback for Broadband Simultaneous Noise and Impedance Matching. IEEE Transactions on Microwave Theory and Techniques, 58(4), 795-806. https://doi.org/10.1109/TMTT.2010.2041570

Chang, K. (2000). RF and Microwave Wireless Systems. (K. Chang, Ed.) (1st ed., Vol. 7). New York: Wiley-Interscience.

Djalil, A., Budianto, \& Sumajudin, B. (2011). Perancangan dan Realisasi Low Noise Amplifier 800MHz. Fakultas Elektro Dan Komunikasi Institut Teknologi Telkom, 1, 1-6. 
Realisasi LNA Dua Tingkat dengan Teknik Penyesuai Impedansi Trafo $\lambda / 4$ dan Lumped Element untuk DVB-T2

Iskander, M. F. (2012). Electromagnetic Fields and Waves(2nd ed.). Utah: Waveland Pres,Inc. Kim, N. Y. (2014). LNA and Mixer for Broadband Digital Video Broadcasting (DVB) Application Using CMOS Process. International Journal of Electrical and Power Engineering, 8(I), 1118.

KOMINFO. (2012). Peraturan Menteri KOMINFO Nomor 5 tahun 2012 tentang Standar Penyiaran Televisi Digital Terestrial Penerimaan Tetap Tidak Berbayar (Free To Air).

Lestari, P. E. W., Endroyono, \& Hendrantoro, G. (2012). Perancangan dan Pembuatan Rangkaian RF Low Noise Amplifier (LNA) Untuk Payload Nano Satelit Frekuensi 145MHz Iinusat-01. Penelitian Strategi Nasional 2012, 1(1), 1-6.

Misran, M. H., MeorSaid, M. A., M.A.Othman, Ismail, M. M., Sulaiman, H. A., \& Cheng, K. G. (2013). Design of Low Noise Amplifier using Feedback and Balanced Technique for WLAN Application. Procedia Engineering, (pp. 323-331. https://doi.org/10.1016/j.proeng.2013.02.042

Motorola Inc. (1994). The RF Line NPN Silicon High-Frequency Transistor BFR96.

Pozar, D. M. (1998). Microwave Engineering. (C. Robey, Ed.) (2nd ed.). New York: John Wiley \& Sons.

Raut, R. L., \& Deshmukh, A. Y. (2014). A 3 to 5GHz Common Source Low Noise Amplifier Using 180nm CMOS Technology for Wireless Systems. International Journal of Computer Engineering and Applications, 5(3), 43-50.

SURJATI, I., ALAM, S., \& NINGSIH, Y. K. (2019). Perancangan dan Realisasi Antena Mikrostrip Log Periodik dengan Elemen Parasitik Air Gap untuk Aplikasi TV Digital DVB-T2. ELKOMIKA: Jurnal Teknik Energi Elektrik, Teknik Telekomunikasi, \& Teknik Elektronika, 72), 324. https://doi.org/10.26760/elkomika.v7i2.324

Taryana, Y., Sulaeman, Y., Wahyu, Y., Armi, N., Paramayudha, K., \& Rojak, R. A. (2015). Design of two stage low noise amplifier using double stub matching network. In 2015 IEEE International Conference on Aerospace Electronics and Remote Sensing Technology (ICARES) (pp. 1-5). IEEE. https://doi.org/10.1109/ICARES.2015.7429833

Tsaraklimanis, A., \& Karagianni, E. (2011). Low Noise Amplifier Design for Digital Television Applications. Journal of Electromagnetic Analysis and Applications, 3(07), 291-296. https://doi.org/10.4236/jemaa.2011.37047

Wibisono, G., Firmansyah, T., \& Ma'arang, D. (2012). Perancangan LNA untuk Radar Automatic Dependent Surveilance- Broadcast (ADS-B) Pada Frekuensi 1090 MHz dengan Multistub Matching. Sistem Kendali Tenaga Elektronika Telekomunikasi Komputer (SETRUM), 1(1), $18-23$. 